\title{
A TRADIÇÃO, A CRÍTICA E AS REPRESENTAÇÕES DA MODERNIDADE EM HOWARD PHILLIPS LOVECRAFT: UMA ANÁLISE TRIANGULAR ENTRE LITERATURA E DOCUMENTOS DE INTIMIDADE
}

\section{TRADITION, CRITICISM AND MODERNITY REPRESENTATIONS IN HOWARD PHILLIPS LOVECRAFT: A TRIANGULAR ANALYSIS BETWEEN LITERATURE AND INTIMITY DOCUMENTS}

Luan Kemieski da Rochal

Resumo: O presente trabalho, intitulado "A tradição, a crítica e as representações da modernidade em Howard Phillips Lovecraft: uma análise triangular entre literatura e documentos de intimidade", trata da relação entre o escritor H. P. Lovecraft e o fenômeno conhecido como modernidade. O principal objetivo do artigo é investigar a compreensão e a resposta do autor acerca do evento da modernidade e os processos modernizadores pelos quais os Estados Unidos passaram. Lovecraft, vivendo no contexto da modernidade, viu sua origem e padrões aristocráticos serem tomados pela nova sociedade que se erguia, ocasionando uma crítica ferrenha aos princípios modernos que ali se faziam presentes: cidades, negros, imigrantes, tecnologia. Conclui-se que Lovecraft é um agente antimoderno, um indivíduo que idealizou uma sociedade utópica com valores considerados "puros". As mudanças sociopolíticas proporcionaram um estímulo que o levou a refletir, por meio da ficção e das cartas, sobre sua nova realidade.

\footnotetext{
${ }^{1}$ Graduado em Licenciatura em História pela Pontifícia Universidade Católica do Paraná (PUC-PR). Atualmente, é mestrando em História na Universidade Federal do Paraná (UFPR). Email para contato: luank.rocha@gmail.com. Endereço para o Currículo Lattes: http://lattes.cnpq.br/9356582523526520.
} 
Palavras-chave: H. P. Lovecraft; Modernidade; Estados Unidos; Literatura.

Abstract: The current paper, entitled "Tradition, criticism and representations of modernity in Howard Phillips Lovecraft: a triangular analysis between literature and documents of intimacy", deals with the relationship between the writer H. P. Lovecraft and the phenomenon known as modernity. The main objective of the article is to investigate the author's understanding and response about the event of modernity and the modernizing processes that the United States went through. Lovecraft, living in the context of modernity, saw its origin and aristocratic standards being taken over by the new society that was rising, causing in a fervent criticism the modern principles that were present there: cities, blacks, immigrants and technology. It is concluded that Lovecraft is an antimodern agent, an individual who idealized a utopian society with values considered "pure". The socio-political changes provided a stimulus that led him to reflect, through fiction and letters, on his new reality.

Keywords: H. P. Lovecraft; Modernity; United States; Literature.

\section{Introdução}

Há um escritor de histórias de terror que foi abraçado pela cultura pop nos dias atuais. Temos filmes, séries de televisão, quadrinhos e várias outras mídias que bebem da fonte dessa pessoa: ele se chama Howard Phillips Lovecraft. Considerado o pai do horror moderno, Lovecraft foi uma figura complexa. Terrores inimagináveis, tentáculos, monstros indescritíveis e ameaças cósmicas são apenas alguns dos elementos característicos de sua obra, e esse nosso autor-fonte viveu na chamada modernidade. 
Durante o século XIX, a dinâmica própria da modernidade influíra em grandes transformações estruturais nas diversas camadas de cultura e convívio humano. Para o historiador Eric Hobsbawm, esse era o século definido pela mudança:

em termos materiais, em termos de conhecimento e de capacidades de transformar a natureza, parecia tão patente que a mudança significava o avanço, que a história moderna parecia sinônimo de progresso (HOBSBAWM, 2016: 48).

O mundo estava eufórico, até mesmo multidões de pessoas comuns acreditavam que o caminho aberto pela modernidade era o melhor a ser seguido. Era no surgimento das novas tecnologias que isso ficava mais visível. Agora as novas fontes de energia, como eletricidade e petróleo, mesmo que não tão significativas, começavam a se tornar viáveis. Também sob cortinas de fumaça as locomotivas surgiam como o símbolo de maior inovação do período: “[...] o conjunto das ferrovias constituía o esforço de construção pública mais importante já empreendido pelo homem" (HOBSBAWM, 2016: 50).

Tais mudanças proporcionaram a vários intelectuais um posicionamento em relação ao que estava acontecendo, entre eles está a figura de H. P. Lovecraft, conhecido pelo seu horror cósmico. Ele nasce em 1890, no apogeu modernizador que os Estados Unidos vinham sofrendo: a época das megalópoles ${ }^{2}$, do intenso fluxo de imigrantes e ferrovias que

${ }^{2}$ Espaço urbano com uma vasta concentração populacional, interligadas entre regiões metropolitanas, como é o caso da costa leste dos Estados Unidos. 
atravessavam o país de costa a costa, conforme reforçado pelo excerto " [...] os Estados Unidos viveram um período de euforia industrial, que louvava o próprio crescimento, capaz de 'integrar o país' e torná-lo competitivo diante das maiores nações industrializadas da Europa" (KARNAL et al., 2018: 156).

Um estudo sobre a modernidade é pertinente devido aos aspectos elementares que influenciam o nosso mundo atual. Somos envolvidos pela modernidade e os processos que dela emergiram. O período do século XIX e XX é o momento da ascensão da burguesia, pensadores com suas visões de mundo instigam e nos fazem refletir sobre nossas ideias. Nossa tecnologia é complementar ao que começou a surgir nos séculos anteriores. Graças ao desenvolvimento dessa modernização, temos acesso às partes mais "obscuras" do planeta. São heranças que atingem os mais diversos âmbitos da nossa vida, como o econômico, político, social e cultural. H. P. Lovecraft é um desses sujeitos que operam de maneiras plurais com relação ao fenômeno da modernidade e suas linhas de força modernizadoras.

$\mathrm{O}$ presente artigo tem como principal objetivo investigar a compreensão da resposta de Lovecraft acerca do fenômeno da modernidade e os processos de modernização pelos quais os Estados Unidos passaram durante o final do século XIX até os anos 30 da primeira metade do século $\mathrm{XX}$, analisando, a partir de suas cartas e contos, as alternativas para o período e suas ideias para uma tradição anterior ao contexto.

\section{O fenômeno da modernidade}


Começar a refletir sobre o termo modernidade com Charles Baudelaire não é algo do acaso. Foi ele quem primeiro lançou essa expressão em seu ensaio "O pintor da vida moderna"” (LE GOFF, 2003: 194), no qual analisa o artista Constantin Guys e os aspectos definidores do que seria a vida moderna. Este é um fenômeno característico das transformações estruturais da sociedade ocidental, tal como um furacão atingindo uma metrópole e fazendo com que tudo que seja sólido se desmanche no ar. São acontecimentos que acabam por mudar nossas concepções de mundo e, ao mesmo tempo, extraem nossas maiores angústias. Resgatar sua historicidade, portanto, é de extremo valor e apresentar suas contradições, particularidades, significados se faz necessária para que compreendamos a concepção lovecraftiana desse evento.

A partir do século XVIII, com o Iluminismo e às vésperas da Revolução Francesa, a ideia de progresso começa a ser adotada. Os homens das Luzes vão substituir a concepção de um tempo cíclico, que aos poucos desloca a noção de superioridade dos antigos sobre os modernos, pelo pensamento de um progresso linear no qual se privilegia, sistematicamente, as personagens recentes.

Concomitantemente, a Revolução Industrial irá transformar radicalmente o debate anterior e mudar as rédeas do que seria conhecido como modernidade. Le Goff (2003) revela-nos que será um período no qual

\footnotetext{
${ }^{3}$ Modernidade no sentido a que costumamos nos referir na linguagem cotidiana e estabelecida nos séculos XIX e XX.
} 
três novos polos de transformação e conflito iriam surgir: o movimento de ordem literária, artística, religiosa e de reação aos padrões até então vistos, chamado "modernismo"; o encontro entre países "desenvolvidos" e países "atrasados", caracterizado pelos problemas do imperialismo chamado "modernização"; e, por fïm, no seio da aceleração da história, na área cultural do ocidente, o aparecimento de um conceito que expande a criação estética, a mentalidade e os costumes: a "modernidade".

Também no século XIX o imperialismo alça voo. As nações atingidas, quando conseguem sua independência, são confrontadas com o problema do atraso em certos campos. Aqui o que se configura na administração mundial é a rivalidade entre nações pela ampliação do mercado consumidor e a busca por lucro e matérias primas, intensificada pela crise econômica que se vivia. Portanto, como diz Eric Hobsbawm (2016: 93), esse é um mundo organizado, “onde os 'avançados' dominariam os 'atrasados"'. A partir de 1880, percebe-se uma tentativa sistemática de conquista, anexando e administrando os países periféricos, partilhando o mundo. Dessa forma, o termo "modernização" e suas ramificações entram em destaque.

É nessa época que o conceito de "modernidade" aparece na perspectiva mais atual. Ela é o resultado das reflexões feitas anteriormente, representando o inacabado, a dúvida, a crítica. "A modernidade é também impulso para a criação, ruptura declarada com todas as ideologias e teorias da imitação" (LE GOFF, 2003: 195). Ela é, como identifica Marshall Berman, um turbilhão de: 
[...] grandes descobertas nas ciências físicas, com a mudança da nossa imagem do universo e do lugar que ocupamos nele; a industrialização da produção, que transforma conhecimento científico em tecnologia, cria novos ambientes humanos e destrói antigos, acelera o próprio ritmo de vida, gera novas formas de poder corporativo e de luta de classes; descomunal explosão demográfica, que penaliza milhões de pessoas arrancadas de seu habitat ancestral, empurrando-as pelos caminhos do mundo em direção a novas vidas; rápido e muitas vezes catastrófico crescimento urbano; sistema de comunicação de massa, dinâmicos em seu desenvolvimento, que embrulham e amarram, no mesmo pacote, os mais variados indivíduos e sociedades; Estados nacionais cada vez mais poderosos, burocraticamente estruturados e geridos, que lutam com obstinação para expandir seu poder; movimentos sociais de massa e de nações, desafiando seus governantes políticos ou econômicos, lutando por obter algum controle sobre suas vidas; enfim, dirigindo e manipulando todas as pessoas e instituições, um mercado capitalista mundial, drasticamente flutuante, em permanente expansão (BERMAN, 1986: 16).

Portanto, a modernidade, para nosso projeto, pode ser entendida como uma agitação de acontecimentos, de permanente desintegração e mudança, de luta e contradição. É um conceito que não é pacífico, mas dinâmico e contraditório, pois apresenta particularidades próprias, crescimento, desilusões e desapontamentos. Aqui entra na discussão a figura de Howard Phillips Lovecraft. ${ }^{4}$

${ }^{4}$ Essa nossa concepção de modernidade bebe das fontes de Le Goff e Berman. É importante salientar que são autores que entram em conflito quando estabelecem o 


\section{O cavalheiro de Providence e o medo da modernidade}

O escritor nasceu em 1890 na cidade de Providence, crescendo e sendo educado como parte de uma aristocracia local. Os anos iniciais de sua vida foram marcados por tragédias, tendo como principais acontecimentos as mortes de seu pai, Winfield Scott Lovecraft, e de seu avô Whipple Van Buren Phillips, ao qual tinha bastante apego. Aliado a isso, por conta da má gestão da herança por parte da família, tiveram que vender a mansão em que viviam e mudar-se para uma pequena casa. Segundo S.T. Joshi (2014: 87), "Lovecraft buscou algum tipo de renovação dos laços de ancestralidade aristocrática e rural para ajudá-lo a sair de um trauma psicológico complicado".

Tal percepção pode ser vista dentro das inúmeras cartas que o escritor veio a escrever:

I am convinced that these customs, perspectives, and imaginative reactions which do most to lend the illusions of direction, interest, significance, and purpose to the formless chaos of human existence, are those which Spring most directly from man's primitive relationship to the earth, its bounties, its cultivation, and its varied phenomena. When agriculture is totally left behind, there grows up about life a sense of instability, artificiality, and ultimate meaninglessness (born of a separation from the visibly eternal and cyclick

conceito desse fenômeno. Portanto, a utilização de tais teóricos nos serviu para historicizar o termo, o primeiro servindo para dar um panorama inicial e geral de como essa concepção se caracteriza, já o segundo nos interessa para dar uma maior profundidade da ideia dentro do contexto em que Lovecraft está inserido. 
prozesses of Nature) which cannot be destructive of the best qualities of civilization. I agree largely with the eminent Spengler when he said that aristocracy is the best form of social organisation possible to mankind. Whilst I have not a personal aptitude for the operations of pastoral and agrestick life, I delight in the Country Squirearchy, in my connection with it... ${ }^{5}$ (LOVECRAFT, 1976: 216).

Esse comportamento aristocrático influenciou no estilo de sua escrita, que acompanhava palavras em inglês arcaico e também em seu racismo e xenofobia.

Lovecraft, após conhecer sua esposa Sonia Greene, se muda com ela para Nova York. É lá que dará início a fase mais produtiva da sua carreira com contos como "O Horror em Red Hook" (1925), "Ele" (1925), “Ar Frio" (1926), “O Chamado de Cthulhu” (1926) etc; e também onde se dará o momento de maior choque de Lovecraft com a modernidade.

${ }^{5} \mathrm{Eu}$ estou convencido que os costumes, as perspectivas e reações imaginativas que fazem mais para emprestar as ilusões de direção, interesse, significado e propósito ao caos sem forma da existência humana, são aqueles que nascem diretamente do relacionamento primitivo do homem com a terra, suas recompensas, seu cultivo e seus variados fenômenos. Quando a agricultura é totalmente deixada para trás, cresce sobre a vida uma sensação de instabilidade, artificialidade, e sem sentido final (nascido de uma separação do visível eternas e cíclicas da natureza) que não podem ser destrutivas das melhores qualidades da civilização. Concordo amplamente com o eminente Spengler quando ele diz que a aristocracia é a melhor forma de organização social possível para a humanidade. Embora não possua aptidão pessoal para as operações da vida pastoral e agropecuária, gosto da pesquisa do país, na minha conexão com ela... (LOVECRAFT, 1976: 216, tradução própria). 
Os Estados Unidos durante esse período estavam em um momento de grande euforia. Com o fim da Guerra de Secessão e a vitória da elite nortenha, o país parte para uma visão política, social e econômica de se modernizar.

Alguns elementos saltam quanto a esse processo de modernização. A lógica da industrialização e as construções de ferrovias que cruzassem o país de norte a sul e leste a oeste. A historiadora Mary Anne Junqueira (2018: 132) relata que:

A intenção era empreender a construção de ferrovias que cortassem o continente a fim de incorporar as terras inóspitas do Oeste, facilitar o estabelecimento de migrantes em regiões desertas, assim como a circulação de mercadorias e o transporte de matérias primas essenciais ao desenvolvimento da indústria.

Para que essa modernidade fosse realizada, uma quantidade enorme de trabalhadores serviram como mão de obra. Ex-soldados da Guerra Civil, brancos pobres e, os principais agentes que Lovecraft irá representar em seus contos e cartas, os imigrantes e negros. Esses, vindos de todos os lugares em busca de emprego, terras baratas, da oportunidade - como ficou conhecido o país -, viviam em condições precárias, com salários mínimos e com enormes riscos de acidentes de trabalho.

Esse fenômeno da vinda de estrangeiros para os Estados Unidos ficou conhecido como A Grande Imigração. Tais indivíduos se instalaram nas grandes cidades que se surgiam no período como Nova York, Chicago e 
Los Angeles, construindo espaços de sociabilidades e lutando pela sua sobrevivência, em um local que fugia das suas referências e origens. Lovecraft os descreve assim:

All life in New York is purely artificial \& affected - values are forced \& arbitrary, mental fashions are capricious, pathological, or commercial rather than authentic, $[\ldots]$. The gracious, glamorous elder New York of dignity \& poise, which lies stark \& horrible \& ghoul-gnawed today beneath the foul claw of the mongrel e misshapen foreing colossus that gibbers $\&$ howls vulgarly \& dreamlessly on its site. [...] There can be no normal American life or thought in a town full of twisted ratlike vermin from the ghetto \& steerage of yesterday - a town where for block on block one can walk whithout seeing a single face which has any relation the life \& growth of the Nordic, Anglo-American stream of civilization. It is not America - is not even Europe - it is Asia \& chaos ${ }^{6}$ (LOVECRAFT, 1968: 100-101).

Em "O Chamado de Cthulhu" apresenta essas pessoas como "mentalmente aberrantes":

${ }^{6}$ Toda vida em Nova York é puramente artificial e afetada - os valores são forçados e arbitrários, a moda mental é caprichosa, patológica ou comercial em vez de autêntica, [...]. A Nova York antiga, glamorosa e de pose digna, fica horrível e corroída pelos carniçais de hoje, sob as garras sujas do colosso estrangeiro vira-lata e deformado, que confusos se jogam de maneira vulgar e sem sonhos em seu local. [...] Não pode haver uma vida americana normal vendo uma cidade cheia de vermes retorcidos como ratos no gueto - uma cidade onde em cada quarteirão não é possível ver um único rosto que tenha qualquer relação com a vida e o crescimento da civilização nórdica e anglo-americana. Isto não é a América - não é nem a Europa - é a Ásia e o caos (LOVECRAFT, 1968: 100-101, tradução nossa). 
Todos os prisioneiros se provaram homens de origem muito baixa e mestiçada, tipos mentalmente aberrantes. A maioria era de marinheiros e alguns poucos negros e mulatos, em grande parte indianos ocidentais ou portugueses de Brava, das ilhas de Cabo Verde, que emprestavam um tom de voduísmo ao culto heterogêneo. Mas antes que muitas questões fossem feitas se tornou manifesto que algo bem mais profundo e antigo do que um simples fetichismo sombrio estava envolvido (LOVECRAFT, 2017: 134).

A vinda de imigrantes e mestiços foi um dos elementos centrais que gerou inquietação entre os norte-americanos nascidos em solo local, estando representado na ficção lovecraftiana. Quando chegaram aos Estados Unidos, a grande maioria dessas pessoas vindas de fora se estabeleceram em associações ou clubes de ajuda mútua. Tal acontecimento fez com que crescesse no imaginário tradicional o sentimento de culto, um lugar em que se apegavam a suas origens e culturas consideradas “estranhas". Lovecraft nutria do mesmo sentimento sendo exposto em grande parte de sua obra:

Em uma clareira natural do pântano havia uma ilha gramada de talvez acre de extensão [...], saltava e se contorcia nessa ilha a horda mais indescritível de anormalidade humana que ninguém, a não ser um Sime ou um Angarola, seria capaz de retratar [...]. Degradadas e ignorantes como eram, as criaturas se apegavam com consistência surpreendente à ideia central de sua abominável fé (LOVECRAFT, 2017: 132-134). 
Grupos infinitos de europeus surgiam como um conglomerado que se afastava do que era considerada a sociedade normal e correta, eram deformadores do mundo, cultuando criaturas, o "degenerado". Lovecraft se vê como um indivíduo da maior pureza. As pessoas, que não fazem parte da linhagem pura e aristocrática, são consideradas "anormais" e "impuras". Essas vêm junto com a modernidade e acabam por "denegrir" seu espaço. Tais pessoas realizavam seu culto nas matas e pântanos, porém, seu habitat era a cidade.

Dentro dessa noção, o escritor também irá apresentar suas representações das cidades em seus textos. A cidade aqui demonstraria o horror racionalizado que a modernidade viria por trazer e, assim, destruir seu "puro" Estados Unidos aristocrático.

O escritor se considerava um cavalheiro com "hábitos superiores", portando-se tal como um lorde e se recusava a trabalhar em empregos “menores”. Segundo Dutra (2013: 95), o aristocrata, para Lovecraft, era aquele "indivíduo responsável pela manutenção e cultivo de valores morais, e principalmente estéticos, de alto padrão - e aponta a gênese do aristocrata no nascimento do conceito da propriedade privada."

É possível ver em seus diários de viagem e suas cartas o que este reparava quando adentrava por regiões novas: "Colonial hillside", "nobler roofs and steeples", "plantations", "ancient roofs". Enfim, esses são substantivos que exemplificam sua percepção e corroboram para nosso ponto. 
Seguindo um "código de cavalheirismo", Lovecraft lê obras dos séculos XVIII e XIX e se visualiza como um nobre. Poetas como Alexander Pope, Edward Plunkett e, principalmente, Edgar Allan Poe foram inspirações para o cavalheiro de Providence. Essa característica aristocrática não fica apenas em seu pensamento, mas também se transfigura em suas obras, tanto no quesito da escrita representada por palavras do inglês antigo, quanto nas histórias como um todo, em descrições, personagens. Vamos pegar como exemplo o seu conto "A busca onírica por Kadath". Essa história tem um dos protagonistas mais famosos de toda obra de Lovecraft: Randolph Carter. Ele é uma espécie de alter ego do escritor, que, como diz Bezarias (2010: 69),

Não suporta a vida insípida, controlada e controladora do mundo moderno, um devaneador devotado à beleza e à nostalgia dos tempos pré-industriais e aos mistérios mais arcanos possíveis, um deslocado em meio à modernidade, que elege chácaras, bosques floridos e campinas bucólicas de uma Nova Inglaterra idílica e identificada como a última manifestação de uma era de ouro perdida, que confunde-se com sua infância.

Nesse conto, acompanhamos a busca de nosso protagonista por uma cidade que acaba por sonhar. Ele recorre aos deuses antigos para ajudá-lo na procura de tal local. Dessa maneira, consegue adentrar no mundo dos sonhos novamente e começa a empreender um percurso que o leve ao seu objetivo. Essa jornada é como se estivéssemos acompanhando um dos diários de viagens de Lovecraft. Nela, Carter retorna às propriedades 
campestres da sua infância, por colinas belíssimas, por bosques, pelas incursões que seus ancestrais fizeram. Finalmente, ao encontrar Kadath, entramos na dimensão que Lovecraft vem enfrentando contra a modernidade: a luta entre seus ideais e aquilo que vem se constituindo na sociedade. A cidade exalava a beleza aristocrata que o protagonista tanto ansiava:

Pois sabe que a tua cidade maravilhosa de ouro e mármore é apenas a soma de tudo o que viste a amaste na tua juventude... a glória dos telhados nas colinas e janelas ocidentais que chamejam ao pôr do sol em Boston; a glória das flores no Common e da grande cúpula na colina e do emaranhado de empenas e chaminés no vale púrpura onde o Charles dormia enquanto corre sob as pontes... essa beleza, moldada, cristalizada e polida por anos de lembranças e de sonhos, é a maravilha dos teus efêmeros terraços ao pôr do sol; e a fim de encontrar aquele parapeito de mármore com curiosas urnas e balaústres entalhados, e de enfim descer os intermináveis degraus que levam à cidade de amplas esplanadas e fontes prismáticas, necessitas apenas voltar aos pensamentos e às visões da tua melancólica infância (LOVECRAFT, 2014: 146).

Porém, ao mesmo tempo, lado a lado de sua beleza, revela-se o medo, o horror cósmico que estava tomando sua idealização e, no fim, era mais um sonho. Ademais, as cidades descritas nos contos de Lovecraft representam também o horror racionalista. Bezarias (2010: 53) descreve que: 
A cidade torna visíveis e incômodas as contradições que, no tempo em que viveu Lovecraft, já não mais podiam ser ocultas por meio da oposição "campo saudável” contra "cidade maligna".

Cthulhu, um dos monstros mais famosos de suas histórias vive na cidade de R'lyeh, um local descrito com:

[...] superfícies grandes demais para pertencer a qualquer coisa própria desta terra [...] a geometria do lugar onírico era anormal, não euclidiana, sugerindo dimensões horrendas e completamente apartadas da nossa [...] Não se podia ter certeza que o mar e a terra eram horizontais, pois a posição relativa de tudo o mais parecia espectralmente variável (LOVECRAFT, 2017: 148-149).

Essas noções enchem o narrador com um pavor que vai ao âmago dos temores que o ser humano pode conceber. A técnica que ergueu esse monumento é tão inumana que produz um horror perante a magnitude, imensidão, que demonstra a indiferença que o universo tem com a humanidade. As cidades ao mesmo tempo em que guardam os segredos que destroem o lugar que o homem se colocou no universo, também expressam o horror imediato de quem as encontra.

A partir da vinda da modernidade e a crítica que o autor faz a ela, Lovecraft irá idealizar uma organização que fuja dessa realidade. Com a Grande Depressão de 1929, o autor começa a refletir que algo de errado estava acontecendo no mundo: desemprego, fome e miséria são pontos que 
se aprofundam ainda mais no período. Dito isso, ele apresenta sua ideia de sociedade ideal ${ }^{7}$.

O importante a ser ressaltado é que, antes da Grande Depressão, Lovecraft, embora fosse um crítico da modernidade - entendida aqui no sentido da estética moderna e da crescente industrialização e urbanização dos anos 20 -, ainda não tinha refletido sobre as formas de organização social alternativas (DUTRA, 2013: 91).

Para isso o escritor escreve o texto "Some Repetitions on the Time" (1933), no qual argumenta que mudanças nas estruturas sociais e econômicas se tornam fundamentais para tirar a população da miséria. Entre essas transformações, são necessários uma melhor distribuição de renda, programas de apoio a desempregados e a indivíduos que vivem na miséria, e a redução de lucros de grandes empresas. O interessante aqui é que, segundo Dutra (2013: 95), "no mundo industrializado, a humanidade chegou a um ponto em que é possível produzir e distribuir recursos materiais de forma igualitária e em quantidade suficiente para todos". Ou seja, a modernidade possibilita uma estrutura para mudanças que antes não se tinha. A manutenção de um sistema social para Lovecraft:

Depende principalmente de manter as massas mais ou menos satisfeitas. Não importa se por meio de instituições sociais e

7 Esse ponto da organização social está em sua grande maioria refletida nas Selected Letters (vol. 5), em que compila suas cartas de 1934 até 1937. Esse é um volume que não tivemos acesso durante a pesquisa, portanto, grande parte das ideias expostas aqui se apoiam em artigos e livros que conversam com o tema. 
políticas (igreja, estado, educação, etc.) ou pela promessa da possibilidade de ascensão social. O importante para uma ordem social funcionar, segundo o autor, é não oprimir as massas em excesso, oferecendo a elas algum tipo de esperança ou compensação dentro do sistema (DUTRA, 2013: 98).

Lovecraft visualiza isso no sistema aristocrático:

Such was the medieval, feudal, or strictly aristocratic alignment. Its strong point was that it gave a small percentage of individuals the carefree leisure and limitless resources which they needed in order to evolve a system of disinterested human values and to develop objects and refinements based on the sheer, uncalculative ideal of intrinsic beauty and innate merit. Just as the earlier barbaric period of physical struggle developed courage, unbrokenness, and those virtues which spring from pride in strength (truthfulness, honour, etc.); so did the feudal-aristocratic period (in which physical strength still played a great part) both confirm these earlier virtues and create additional graces based on logic, beauty knowledge, and expanded and sensitized human faculties (LOVECRAFT, 2006: 105). ${ }^{8}$

${ }^{8}$ Tal foi o arranjo, seja medieval, feudal, ou estritamente aristocrático. Seu ponto forte foi dar a uma pequena porcentagem de indivíduos os lazeres despreocupados e os recursos ilimitados que eles precisavam, a fim de desenvolverem um sistema de valores humanos e refinamentos com base no ideal puro de beleza intrínseca e méritos inatos. Assim como o período bárbaro anterior de luta física desenvolveu a coragem, a resiliência, e essas virtudes brotam do orgulho na força (honra, verdade, etc.), da mesma forma o posterior período feudal-aristocrático (em que a força física ainda teve sua parcela de importância), confirmou tanto estas virtudes anteriores como também criou qualidades adicionais com base na lógica, conhecimento, beleza, que expandiram e sensibilizaram o espírito humano (LOVECRAFT, 2006: 105, tradução própria). 
No final, por mais que Lovecraft tenha acreditado que a sociedade aristocrática era a melhor, ele já se via desiludido com o processo para essa restauração. Segundo Joshi (2003: 112):

He still felt it possible to reverse the tide of mechanisation and return to the rural-based aristocracy of the past; but with the writing of "Some Repetitions on the Times" and "The Shadow out of Time," we see that Lovecraft has accepted the inevitability of a mechanised future - though by no means sympathising with it - and feels that proper education and the reorganisation of society (particularly the abolishment of democracy and capitalism) could perhaps provide meaningful and aesthetically satisfying existence. Lovecraft had ceased to want a restoration of the past, but now looks to reform for the future. ${ }^{9}$

Portanto, a modernidade para Lovecraft foi um fenômeno que veio para destruir a tradição e os valores da pureza aristocrática - a qual ele considerava a correta. Dessa forma, a modernidade trouxe consigo, por meio de rápidas transformações, a incorporação de olhares diversos, provindos das vivências de imigrantes e negros, os quais, na visão do

\footnotetext{
${ }^{9}$ Ele ainda acreditava ser possível reverter o processo de mecanização e voltar para a aristocracia rural do passado, mas com a escrita de "Some Repetitions on the Times" e A Sombra vinda do Tempo', percebemos que Lovecraft aceitou a inevitabilidade de um futuro mecanizado, embora de maneira alguma simpatize com isso e acredite que uma educação adequada e a reorganização da sociedade (principalmente com a abolição da democracia e do capitalismo) talvez pudesse proporcionar uma existência digna e esteticamente agradável. Lovecraft deixou de desejar uma restauração do passado para desejar uma reforma do futuro (JOSHI, 2003: 112, tradução própria).
} 
escritor, deturpavam os valores sociais aristocráticos. Essa modernidade, alinhada à ideia de racionalização e de progresso, transfigurada na industrialização, acabava com os princípios mais belos que um povo poderia ter, levando-os a uma suposta perdição.

\section{Considerações finais}

O presente trabalho visou a compreender como a modernidade e os processos de modernização nos Estados Unidos do final do século XIX e início do XX foram respondidos por H. P. Lovecraft, levando em consideração suas cartas e suas produções literárias.

Assim, a modernidade é um fenômeno instigante que nos permite compreender os Estados Unidos e a figura de Lovecraft. Ela fornece uma janela para a sociedade da época, mas, mais do que isso, ela permite que seu autor e suas crenças e ideologias sejam estudados, pois, com suas cartas e contos, Lovecraft imprime sua perspectiva dentro de sua obra.

As características relacionadas ao contexto, tanto biográfico quanto histórico, representam o escritor como uma pessoa com valores aristocráticos bem enraizados na sua concepção de mundo. Esse é um ponto norteador de grande parte de sua produção. A representação idealizada e a impressão de vivacidade que seus escritos carregam impedem que elas sejam consideradas retratos fiéis da realidade do período. Elas foram construídas e carregam o olhar do viajante sobre as cenas no cotidiano.

\section{Referências}


BERMAN, Marshall. Tudo o que é sólido desmancha no ar: a aventura da modernidade. São Paulo: Companhia das Letras, 1986.

BEZARIAS, Caio Alexandre. A totalidade pelo horror - o mito na obra de Howard Phillips Lovecraft. São Paulo: Annablume, 2010.

DUTRA, Daniel Iturvides. A utopia na obra de H. P. Lovecraft: uma leitura política de At The Mountains of Madness. Cadernos do IL (UFRGS), v. 45, p. 86-108, 2013.

HOBSBAWM, Eric J. A era dos impérios: 1875-1914. São Paulo: Paz e Terra, 2016.

JOSHI, Sunand Tryambak. A Vida de H. P. Lovecraft. São Paulo: Hedra, 2014.

Press, 2003.

. Primal Sources: Essays on H. P. Lovecraft. New Jersey: Wildside

JUNQUEIRA, Mary Anne. Estados Unidos: Estado Nacional e Narrativa da Nação (1776-1900). São Paulo: Edusp, 2018.

KARNAL, Leandro et al. História dos Estados Unidos: Das Origens ao Século XXI. 3 ed. São Paulo: Contexto, 2014.

LE GOFF, Jacques. História e Memória. 5 ed. São Paulo: Editora Unicamp, 2003.

\section{Fontes}

LOVECRAFT, Howard Phillips. A busca onírica por Kadath. In:

Os melhores contos de H. P. Lovecraft. São Paulo: Editora Hedra, 2014.

. O chamado de Cthulhu. In: . H. P. Lovecraft: Medo clássico. Rio de Janeiro: Darkside, 2017. . Selected Letters (1925-1929). Sauk City: Arkham House, 1968. 
Cadernos de Clio, Curitiba, v. 12, $n^{\circ} .1,2021$

. Selected Letters (1932-1934). Sauk City, Arkham House, 1976.

. Some Repetitions on the Times. In:

. Collected Essays

Volume 5 - Philosophy Autobiography \& Miscellany. New York: Hippocampus Press, 2006.

Recebido em: 22/02/2021 Aceito em: 16/11/2021 